\title{
VIVÊNCIA DE MULHERES EM SITUAÇÃO DE PRISÃO QUANTO A ASSISTÊNCIA RECEBIDA NO CICLO GRAVÍDICO PUERPERAL
}

\author{
WOMEN IN PRISION SITUATION EXPERIENCE FOR ASSISTANCE \\ RECEIVED IN CYCLE GRAVID PUERPERAL
}

\author{
Hanna Paula da Silva dos Santos', Rebeca Cardoso Gazineu2, Tânia Christiane Ferreira Bispo³ \\ 'Graduanda de Enfermagem da Escola Bahiana de Medicina e Saúde Pública. Salvador, Bahia, Brasil. hanna_paula15@hotmail.com \\ ${ }^{2}$ Graduanda de Enfermagem da Escola Bahiana de Medicina e Saúde Pública. Salvador, Bahia, Brasil. becagazineu@gmail.com \\ ${ }^{3}$ Enfermeira. Doutora em Saúde Coletiva. Professora na Universidade do Estado da Bahia. Salvador, Bahia, Brasil. taniaenf@uol.com.br
}

RESUMO | A população nacional carcerária feminina vem crescendo expressivamente, mas ainda nota-se que há uma ausência de políticas públicas efetivas a esta demanda. Dentro dessa população crescente de mulheres, muitas têm obtido a experiência de gestar e parir em situação prisional. $O$ presente estudo teve como objetivo compreender a vivência de mulheres em situação de prisão quanto à assistência recebida no ciclo gravídico puerperal. Tratou-se de uma pesquisa de campo, de caráter qualitativo, no qual foram realizadas 06 entrevistas com mulheres que vivenciaram o ciclo gravídico puerperal em situação de prisão, em um complexo penitenciário da cidade de Salvador/ BA. Por se tratar de um recorte de um projeto maior, já se encontrava aprovado pelo Comitê de Ética com parecer de número 346.920. Os resultados obtidos evidenciaram que a experiência vivenciada pela população feminina em situação de prisão, quanto ao acompanhamento durante o ciclo gravídico puerperal dentro da instituição, demonstrou precariedade da assistência voltada para consultas médicas, transporte, alimentação e aporte de medicamentos. Já no âmbito hospitalar, revelou-se uma assistência efetiva, sem demonstração de discriminação, tendo maior acessibilidade de atendimento. Diante dessa perspectiva, torna-se indispensável a reavaliação da qualidade da assistência proporcionada a essas mulheres, durante o ciclo gravídico puerperal, garantindo um atendimento humanizado, assegurando a peculiaridade no processo do nascimento, preservando os seus direitos, sua autonomia e influenciando a participação ativa durante todo o período.

\begin{abstract}
The national female prison population has grown significantly, yet we note that there is an absence of effective public policies to this demand. Within this growing population of women, many have obtained gestate and give birth experience in the prison situation. This study aimed to understand the experience of women in prison situation regarding the care received in the puerperal pregnancy cycle. This was a field research, qualitative, in which were conducted 06 interviews with women who experienced pregnancy and childbirth in prison situation in a prison complex in the city of Salvador / BA. Because it is a cutout of a larger project, it was already approved by the Ethics Committee with opinion number 346,920. The results showed that the situation experienced by the female population in prison situation, the monitoring during pregnancy puerperal cycle within the institution, demonstrated the precariousness of targeted assistance for medical appointments, transportation, food and drug supply. In the hospital environment, effective assistance proved without proof of discrimination, and greater accessibility of care. Given this perspective, it is essential to reassess the quality of care provided to these women during pregnancy and childbirth, ensuring humane care, ensuring the uniqueness in the birth process, preserving their rights, autonomy and influencing the active participation throughout the period.
\end{abstract}

Keywords: Women's Health; prisons; Human rights; pregnant women; Delivery of Health Care

Palavras-chave: Saúde da Mulher; Prisões; Direitos

Humanos; Gestantes; Assistência à Saúde. 


\section{INTRODUÇÃO}

O sistema prisional brasileiro apresenta uma desestruturação marcada pelo abandono, falta de investimento e descaso do poder público, vinculada a uma demora acentuada na concessão de benefícios aos detentos, $\circ$ que caracteriza sua evidente fragilidade'. Essa realidade se intensifica quando os estabelecimentos são destinados às mulheres.

A mulher que se encontra em situação de privação de liberdade é submetida a uma condição de invisibilidade, o que ratifica e acentua as marcas da desigualdade de gênero a qual são submetidas na sociedade brasileira ${ }^{2}$. Esse cenário tem levantado questionamentos de gestores, educadores e profissionais, principalmente no que tange as ações de saúde prestadas no sistema penitenciário, em especial a saúde reprodutiva ${ }^{3}$.

A população nacional carcerária feminina vem crescendo expressivamente, mas ainda nota-se que há uma ausência de políticas públicas efetivas a esta demanda ${ }^{3}$. Dentro dessa população crescente de mulheres, muitas têm obtido a experiência de gestar e parir em situação prisional.

A maternidade, mesmo quando desejada, envolve uma mistura de sentimentos e expectativas, os quais se intensificam principalmente quando relacionado às mulheres em situação de prisão, visto que já se encontram sensibilizadas pela condição vigente.

Dentro dessa realidade, as mulheres, a partir do momento de sua reclusão, vivenciam uma experiência segregadora, no que diz respeito à violação dos direitos humanos, especialmente quando voltados às gestantes e puérperas ${ }^{4}$. Isso se deve, sobretudo, ao estigma imposto pela sociedade referente aos desvios do padrão de conduta, ou seja, a partir do momento em que o indivíduo tem comportamentos que divergem dos princípios legislativos, automaticamente, ele passa a perder seus direitos como cidadão.

O Ministério da Saúde junto ao Ministério da Justiça, instituiu no ano de 2004 o Plano Nacional de Saúde no Sistema Penitenciário através da Portaria Interministerial n. ${ }^{\circ} 1.777$, de 9 de setembro de 2003, que tem como objetivo prover a atenção integral à saúde da população penitenciária brasileira. $\bigcirc$ plano também enfatiza que é necessário reforçar a ideia de que as pessoas em situação de prisão, independente da natureza do seu delito, mantêm todos os direitos fundamentais, e principalmente o direito de gozar dos mais elevados padrões de saúde física e mental ${ }^{5}$.

Segundo a constituição, o acesso à saúde é direito de todos e dever do Estado. Dessa forma, para garantir os direitos da mulher presa, foi instituída a Lei $n^{\circ} 11.942$, no ano de 2009, que determinou que às gestantes presidiárias fosse assegurado de forma humanizada o acompanhamento médico, principalmente durante o pré-natal e puerpério ${ }^{6}$.

Em dezembro de 2010, a Assembleia Geral da ONU aprovou as regras mínimas para o tratamento da presidiária e medidas não privativas de liberdade para as mulheres infratoras, chamadas Regras de Bangkok (Regras das Nações Unidas). Essas Regras propõem um olhar diferenciado para as especificidades de gênero no encarceramento feminino, tanto no campo da execução penal, como também na priorização de medidas não privativas de liberdade, ou seja, que evitem a entrada de mulheres no sistema carcerário ${ }^{7}$.

Para também fomentar $\circ$ direito dessa mulher em situação de prisão, em 16 de Janeiro de 2014, ○ Ministério da Justiça, através da Portaria Interministerial $n^{\circ} 210$, instituiu a Política Nacional de Atenção às Mulheres em Situação de Privação de Liberdade e Egressas do Sistema PrisionalPNAMPE, com o objetivo de reformular as práticas do sistema prisional brasileiro, contribuindo para a garantia dos direitos das mulheres nacionais $e$ estrangeiras ${ }^{8}$.

As histórias das mulheres na busca pelos serviços de saúde expressam discriminação, frustrações e violações dos direitos. Isso se dá principalmente quando essas mulheres vivenciam um contexto prisional. A qualidade da atenção em saúde junto à humanização é um processo contínuo e essencial para que as ações de saúde se traduzam na resolutividade dos problemas levantados, na satisfação das usuárias, na promoção do autocuidado e no reconhecimento aos seus direitos? 
Nesse contexto, a promoção, prevenção e atenção integral à saúde das mulheres em situação de vulnerabilidade maior, como é o caso das mulheres em situação de prisão, além de ser uma responsabilidade do Estado, representa uma missão e um desafio para profissionais de saúde e cidadãos que acreditam numa sociedade sem excluídos 5 . Diante desta problemática, voltada para mulheres que vivenciam esse contexto de violação dos direitos humanos, surgiu a seguinte questão norteadora: como é a vivência de mulheres em situação de prisão quanto a assistência recebida no ciclo gravídico puerperal?

Dessa forma, a relevância do presente estudo esteve em considerar o presídio como um campo significativo, por diminuir o espaço existente na literatura sobre a temática, fortalecer e melhorar a qualidade da assistência prestada, valorizando a humanização, e fomentar as discussões sobre a maternidade em situação de privação de liberdade. Tal fato despertou o interesse na confecção do estudo, que teve como objetivo geral compreender a vivência de mulheres em situação de prisão quanto à assistência recebida no ciclo gravídico puerperal; e como objetivos específicos: a) caracterizar o perfil de mulheres que gestaram e/ou pariram no contexto prisional; b) relatar a vivência de mulheres em situação de prisão sobre o seu ciclo gravídico puerperal.

O interesse pelo tema se deu em decorrência da nossa participação no Projeto "Ser Mulher, estar grávida e presidiária: difíceis caminhos", do Núcleo de Pesquisa Interfaces em Saúde - NUPEIS da EBMSP, onde tivemos a oportunidade de conhecer - complexo penitenciário feminino e desenvolver oficinas de educação em saúde a gestantes e puérperas em situação de prisão. Nestas oficinas estivemos destinadas a ouvir o relato dessas mulheres, quanto à assistência recebida no contexto prisional, conhecendo um pouco da realidade vivenciada por elas no que se refere ao ciclo gravídico puerperal fora do ambiente familiar. Durante esses momentos, muitas compartilharam seus medos, suas ansiedades e angústias, visto que é uma fase marcada por inúmeras transformações nas suas vidas.

Passar esse período em situação de prisão se constitui algo extremamente angustiante e nos instigou a aprofundar mais acerca da temática, tendo como finalidade o fortalecimento e melhoria da qualidade da assistência prestada a essas mulheres, valorizando a humanização. $O$ tema mostra-se relevante também pela escassez de produção científica.

\section{MÉTODO}

Tratou-se de uma pesquisa de campo exploratória com abordagem qualitativa. Fonseca ${ }^{10}$ define pesquisa de campo como investigações em que, além da pesquisa bibliográfica e/ou documental, realiza-se a coleta de dados junto a pessoas. $O$ caráter exploratório por sua vez, proporciona maior familiaridade com o problema, com intuito de torná-lo mais explícito ou a construir hipóteses, levando a uma análise de exemplos que estimulem a compreensão" ${ }^{1}$. O enfoque qualitativo é utilizado, segundo Gerhardt; Silveira ${ }^{12}$ para compreender e explicar a dinâmica das relações sociais, preocupando-se com aspectos reais que não podem ser quantificados.

Esse estudo foi realizado em um Conjunto Penal Feminino localizado em um Complexo Penitenciário situado na cidade de Salvador - BA. Foram analisadas mulheres que gestaram e/ou pariram em situação de prisão, que desejaram participar da pesquisa e assinaram o Termo de Consentimento Livre e Esclarecido.

Para participação da pesquisa, utilizou-se como critério de inclusão: gestantes e/ou puérperas que estiveram dispostas a participar do presente estudo; e como critério de exclusão: mulheres que estavam contra indicadas pela psicóloga do presídio a participar da pesquisa.

A pesquisa foi realizada no período de Abril a Maio de 2016. Por se tratar de um recorte de um projeto de extensão denominado: 'SER MULHER, ESTAR GRÁVIDA E PRESIDIÁRIA: DIFÍCEIS CAMINHOS', que foi cadastrado na Plataforma Brasil, iá encontrase aprovado pelo Comitê de Ética, sob parecer de número (346.920; CAAE 16185513.5.0000.0057), de acordo com a Resolução $n^{\circ}(466 / 2012)$, do Conselho Nacional de Saúde.

Como forma de instrumento de coleta, foram realizadas 6 entrevistas semiestruturadas com 
mulheres que gestaram ou pariram em ambiente prisional. Esse tipo de entrevista é aplicado quando se pretende delimitar o volume das informações, alcançando assim um direcionamento maior para o tema, intervindo a fim de que os objetivos sejam atingidos $^{13}$. As mulheres foram abordadas $e$ informadas sobre a pesquisa, suas peculiaridades e seus direitos, tendo garantida a total liberdade para esclarecimento de dúvidas. Posteriormente, assinaram $\circ$ Termo de Consentimento Livre e Esclarecido, no qual foi levado em consideração o direito à recusa em responder as questões solicitadas. As entrevistas foram transcritas e analisadas em seguida. Para preservar a identidade das participantes, optamos em utilizar nome de pedras preciosas para identifica-las.

Inicialmente, foi caracterizado o perfil das mulheres entrevistadas; em seguida, foi realizada a análise de dados, através da técnica de análise de conteúdos que, segundo Minayo ${ }^{14}$, consiste na verificação de hipóteses e/ou questões, levando à respostas para as questões formuladas e até possíveis confirmações para as hipóteses estabelecidas antes do processo de investigação.

Essa técnica foi concretizada a partir de uma pré-análise, onde os pressupostos e as questões norteadoras foram formuladas; em seguida, houve a exploração do material e posterior verificação e interpretação dos resultados obtidos. Desse modo, foram utilizadas para a análise as etapas definidas pela mesma autora, que fundamenta-se em préanálise, exploração do material, tratamento dos resultados obtidos e interpretação.

\section{RESULTADOS E DISCUSSÃO}

Foram realizadas 6 entrevistas e, a partir delas, estabeleceu-se a caracterização do grupo e identificada 01 categoria: 1) Vivência de mulheres em situação de prisão quanto a assistência recebida no ciclo gravídico puerperal, que teve como subcategorias: 1.1) Vivência no presídio, 1.2) Vivência no âmbito hospitalar.

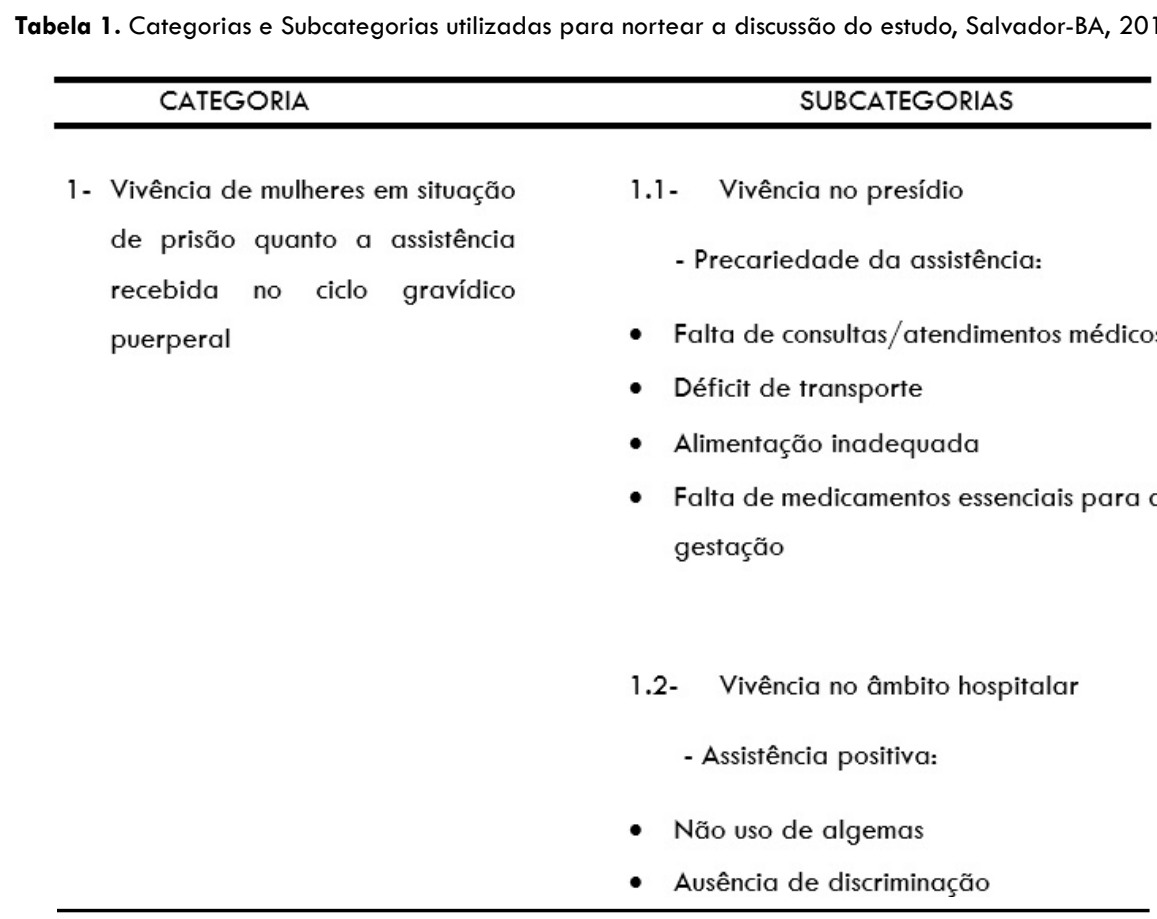

Fonte: Elaborado pelas próprias autoras. 
Neste estudo, realizado com 6 mulheres em situação de prisão, percebeu-se que as participantes possuem faixa etária entre $20-25$ anos (50\%) e 26-30 anos (50\%), ou seja, em pleno período economicamente ativo da vida, indo de acordo com o DEPEN(15), que afirma que o perfil etário da mulher encarcerada se encontra abaixo dos 34 anos. Referente ao estado civil, $100 \%$ das reclusas entrevistadas são solteiras, o que pode ser explicado pelo crescimento ascendente de jovens no sistema prisional.

Com relação à raça, Bispo et $\mathrm{al}^{3}$ elenca a raça negra como prioritária, divergindo assim do resultado do nosso estudo, no qual as mulheres entrevistadas, em sua maioria, declararam -se pardas. No quesito escolaridade, a maioria das participantes informaram ter $1^{\circ}$ grau incompleto, convergindo com os estudos de Bispo et $\mathrm{al}^{3,16}$, confirmando assim que $\circ$ grau de escolaridade se apresenta baixo no geral da população em situação prisional.

Tabela 2. Caracterização das mulheres privadas de liberdade entrevistadas, quanto a faixa etária, estado civil, raça e escolaridade, Salvador-BA, 2016.

\begin{tabular}{|c|c|c|}
\hline Faixa Etária & $\mathbf{N}^{\circ}$ & $\%$ \\
\hline 20-25 anos & 3 & 50 \\
\hline 26-30 anos & 3 & 50 \\
\hline Total & 6 & 100 \\
\hline Estado Civil & $\mathbf{N}^{\circ}$ & $\%$ \\
\hline Solteira & 6 & 100 \\
\hline Casada & 0 & 0 \\
\hline Total & 6 & 100 \\
\hline Raça & $\mathbf{N}^{\circ}$ & $\%$ \\
\hline Parda & 4 & 66,7 \\
\hline Branca & 1 & 16,7 \\
\hline Preta & 1 & 16,7 \\
\hline Total & 6 & 100 \\
\hline Escolaridade & $\mathbf{N}^{\circ}$ & $\%$ \\
\hline $1^{\circ}$ Grau Incompleto & 4 & 66,7 \\
\hline $1^{\circ}$ Grau Completo & 1 & 16,7 \\
\hline $2^{\circ}$ Grau Incompleto & 1 & 16,7 \\
\hline Total & 6 & 100 \\
\hline
\end{tabular}

Fonte: Elaborado pelas próprias autoras.

Analisando o motivo de reclusão, notou-se que, em sua maioria, estão associados ao tráfico de drogas e homicídios (33,3\% cada), compatibilizando com os estudos de Nicolau ${ }^{17}$, que evidenciam o tráfico de drogas como principal razão de encarceramento feminino. Porém com atual o estudo, se percebeu um notável crescimento de casos de homicídios associados às mulheres em situação de prisão. 
Tabela 3. Identificação de mulheres privadas de liberdade quanto ao motivo de reclusão, Salvador - BA, 2016

\begin{tabular}{lcc}
\hline Motivo de Reclusão & $\mathbf{N}^{\circ}$ & $\%$ \\
\hline Tráfico & 2 & 33,3 \\
Homicídio & 2 & 33,3 \\
Sequestro & 1 & 16,7 \\
Assalto & 1 & 16,7 \\
Total & 6 & 100 \\
\hline
\end{tabular}

Fonte: Elaborado pelas próprias autoras.

VIVÊNCIA DE MULHERES EM SITUAÇÃO DE PRISÃO QUANTO A ASSISTÊNCIA RECEBIDA NO CICLO GRAVÍDICO PUERPERAL:

Através das entrevistas realizadas com as mulheres que vivenciaram o ciclo gravídico puerperal dentro do ambiente prisional, foi possível analisar como elas se sentiram ou se sentem em relação à assistência recebida durante toda a sua fase de gestação e puerpério. Desse modo, foram traçadas as seguintes subcategorias: Vivência no presídio, e Vivência no âmbito hospitalar.

\section{VIVÊNCIA NO PRESÍDIO:}

No Brasil, a grave circunstância em que se encontram as pessoas em situação de privação de liberdade é um fato, ponderado, principalmente, nas práticas de violência, precariedade de espaço físico e na carência do atendimento à saúde ${ }^{18}$. A falta de diligência ocorrida dentro das instituições e executada pelas diversas administrações penitenciárias femininas no país é demonstrada através da carência de condições básicas de funcionamento. A superlotação, a falta de colchões, oferta de alimentação imprópria para consumo, instalações sanitárias deficientes, falta de atividades de lazer, baixa oferta de educação e trabalho são alguns dos desrespeitos vivenciados por mulheres em situação de prisão ${ }^{19}$.

Após a análise de dados referente aos depoimentos das participantes, percebeu-se, através de suas falas que há uma precariedade na assistência dentro do estabelecimento penal, voltada para a falta de consultas/atendimentos médicos, déficit de transporte, alimentação inadequada e falta de medicamentos essenciais para a gestação, ○ que não condiz com o assegurado pela Lei de Execução Penal $n^{\circ} 11.942$, que trata a respeito das garantias de condições mínimas de assistência às mães sobre regime de privação de liberdade, garantindo à mulher o direito a acompanhamento médico ${ }^{6}$.

Diante desta situação, foi evidenciado que a maioria das mulheres não obtiveram a quantidade de consultas pré-natais necessárias para o acompanhamento adequado do bebê, sendo constatado a partir deste fato que algumas delas não tinham o conhecimento em relação ao tempo gestacional, além de também não poder, na própria consulta, desfrutar de ouvir o som das batidas do coração dos seus filhos.

Foi observado também a dificuldade em realização de exames de imagem, devido ao déficit de meios de transporte para locomover essas mulheres; tornase notável a insatisfação gerada diante da situação no relato feito por Pérola:

[...] A pessoa com seis meses no lugar e não sabe como o bebê está, como no dia não teve escolta pra levar...não fiz a ultrassom. (Pérola)

[...] Só avaliou a barriga, pesou e mediu...olhou os peitos (Pérola)

A entrevistada Rubi também demonstrou insatisfação quando indagada em relação ao acompanhamento médico dentro do presídio, reforçando o relato anterior.

[...] Você tem que chutar portão pra ser atendida. 
Se sentir dor, tem que querer arrombar, fazer zuada [...] as vezes não tem médico na casa. Tive que xingar e brigar pra fazer ultrassom, senão eu não fazia....só fiz ultrassom porque corri muito atrás. (Rubi)

Segundo Lucyk e Furumoto ${ }^{20}$, as necessidades de ferro, zinco, iodo, vitamina $A$ e vitamina $C$ aumentam com intuito de propiciar o saudável desenvolvimento e desfecho gestacional com sucesso para a mãe e o feto, por isso torna-se indispensável uma alimentação diferenciada durante esse período. Todavia, as participantes do estudo, quando questionadas sobre a alimentação que era ofertada no ambiente prisional, relataram que não existia uma dieta específica e nutritiva para aquelas que estavam gerando ou amamentando o seu filho, e que muitas vezes só se alimentavam porque a família levava a refeição para elas.

[...]As vezes eu nem como...eu como quando minha mãe traz. Às vezes passo o dia inteiro. A comida é sem sal e é a mesma comida pra todo mundo (Rubi)

"A comida daqui vem muito cedo! Umas quatro horas da tarde, mais tarde já tô com fome." (Pérola)

Além disso, as depoentes manifestaram a falta de medicamentos essenciais para uma gestação adequada, como o ácido fólico, que é requisito fundamental para o crescimento adequado durante a gestação e lactação, e também para a formação de anticorpos ${ }^{21}$.

"O sulfato ferroso demora pra chegar. Tem que ficar insistindo. Às vezes ele fala: 'Não tem remédio na casa'." (Pérola)

Perante estes relatos, torna-se notório a carência existente na assistência das presidiárias dentro do complexo penitenciário, contrastando com as Diretrizes Estratégicas do Plano Nacional de Saúde no Sistema Penitenciário, que afirma uma assistência integral resolutiva e de qualidade às necessidades de saúde da população penitenciária ${ }^{5}$.

Sabe-se que a atenção humanizada depende do fornecimento dos recursos necessários, da organização de rotinas com procedimentos benéficos, evitando intervenções inoportunas, e do estabelecimento de relações pautadas em princípios éticos, com garantia de privacidade e autonomia. É essencial também compartilhar com a mulher e sua família as decisões sobre as condutas a serem adotadas ${ }^{22}$. O que se percebe, é que essa assistência ainda é uma prática muito distante da realidade das experiências vivenciadas dentro do sistema prisional.

\section{VIVÊNCIA NO ÂMBITO HOSPITALAR:}

A experiência de gestar pode possibilitar à mulher uma nova perspectiva de vida, contribuindo para o seu crescimento emocional e pessoal, visto que, segundo Barros" ${ }^{23}$, "é um evento singular que envolve experiências afetivas". As modificações que esse processo promove no organismo da mulher não estão relacionadas apenas às mudanças físicas, mas envolvem também o emocional ${ }^{22}$, já que os sentimentos como a ansiedade e o medo, atrelado às expectativas geradas, expressam também, na maioria das vezes, a insegurança em relação ao futuro. Nesse sentido, ser mulher, estar grávida e em situação de prisão, revela momentos difíceis para essa população.

Explorando os depoimentos coletados, constatou-se que há uma assistência efetiva dentro do ambiente hospitalar, marcada pela ausência de discriminação e $\circ$ não uso de algemas durante $\circ$ trabalho de parto. Isso demonstra uma assistência humanizada por parte dos profissionais de saúde que colocam em prática $\circ$ que se refere às Políticas Públicas destinadas à saúde da mulher.

Para Oliveira, Collete, Viera ${ }^{24}$, humanizar é possibilitar o diálogo nas relações e interações humanas, não utilizando-o apenas como uma técnica de comunicação verbal, mas sim como forma de conhecer o outro, estabelecendo metas conjuntas que propiciem o bem estar recíproco. Ou seja, acolher a mulher, reconhecendo a sua individualidade $e$ percebendo suas necessidades e capacidade de lidar com o processo do nascimento.

Acolher implica desde a recepção da mulher que chega a unidade, responsabilizando-se por ela, ouvindo suas queixas, permitindo que ela expresse suas preocupações e angústias, garantindo atenção resolutiva e articulação com os outros serviços de saúde para a continuidade da assistência, quando 
necessário ${ }^{22}$. Sendo assim fica claro uma assistência positiva relatada por Esmeralda.

[...] Eu achei que eles cuidaram de mim bem...o atendimento foi melhor do que dos outros filhos fora da cadeia. (Esmeralda)

[...]Eu senti, de verdade, pensava que no mundo não tinha gente boa, mas eu paguei com a língua...Eles me tratou como gente, com educação. Não tenho nada de reclamar. (Esmeralda)

Estas falas viabilizam algumas indagações pertinentes quanto ao atendimento recebido, possibilitando reflexões acerca da priorização do cuidado: Será que esse atendimento foi melhor devido ao fato dessa mulher estar sob tutela do Estado? Será que se deu a partir do medo, por parte dos profissionais, referente ao contexto que essas mulheres estão inseridas?

Vale a pena refletir acerca dessas questões, pois, caso a resposta seja afirmativa para a primeira indagação, certamente irá demonstrar que a diretriz da Política Nacional de Atenção Integral à Saúde da Mulher, que implica no estabelecimento de relações com pessoas singulares, através do respeito a todas as diferenças, sem discriminação de qualquer espécie ${ }^{18}$, não está sendo praticada quando essas mulheres estão ausentes da vigilância do Estado.

Caso a segunda indagação seja afirmativa, tornase indispensável salientar os direitos garantidos pela constituição à essas mulheres, sensibilizando e resgatando valores das condutas por parte dos profissionais que as assistem, para que possam desenvolver o seu trabalho com ética e respeito.

No quesito uso de algemas durante o trabalho de parto, as depoentes relataram que não as utilizaram no decorrer do processo.

"Não fui algemada não! Só ficava algemada quando a agente saía para lanchar" (Safira)

"No dia que fui pari, foi tudo bem! Tem essa coisa de algemar as pessoas, mas não me algemaram [...] Quando a gente ia toma café, que algema. Quando ia no refeitório, mas quando voltava, tirava algema" (Quartzo)
Esse fato é consonante com o Decreto aprovado em setembro de 2016, que regulamenta o disposto no art. 199 da Lei $n^{\circ} 7.210$, de 11 de julho de 1984 . Este Decreto afirma a proibição da utilização de algemas em mulheres presas durante e após o trabalho de parto, e no trajeto da parturiente entre a unidade prisional e a unidade hospitalar ${ }^{25}$.

Sendo assim, percebeu-se uma assistência benéfica proporcionada, com atendimento humanizado, que engloba essas mulheres que se encontram em situação de prisão, visto que o objetivo principal sempre deve ser a garantia da qualidade no processo do nascimento, a prevenção da morbimortalidade materna e perinatal, evitando intervenções desnecessárias e preservando sua privacidade e autonomia.

\section{CONSIDERAÇÕES FINAIS}

Diante dessa perspectiva, o estudo revelou que - público carcerário feminino é marcado por uma população jovem e, através dos relatos das participantes, compreendemos que há uma grande diferença na assistência entre o âmbito presidiário e o hospitalar, visto que no ambiente hospitalar a atenção a saúde se mostrou mais efetiva.

Este fato não era o esperado, pois em decorrência do estigma imposto pela sociedade, referente aos desvios de padrões de conduta, imagina-se que essas mulheres sofram discriminação. Sabendo que $\circ$ acesso à saúde é direito de todos e dever do Estado, esse resultado, referente ao contexto prisional, caracteriza uma violação dos direitos humanos.

Ao analisar a vivência das gestantes e puérperas em situação de prisão, podemos afirmar a vulnerabilidade das mulheres que vivem nesse contexto. No que diz respeito a assistência que the é prestada, torna-se indispensável a reavaliação da qualidade do cuidado prestado, garantindo um atendimento integral, humanizado, preservando os seus direitos, sua autonomia, estabelecendo uma relação de confiança e influenciando a participação ativa durante todo o período. 
Para isso, faz-se necessária a implementação de novas medidas eficazes que contribuam para garantia dos direitos humanos, tais como a fiscalização do sistema penitenciário e das condutas dos profissionais, que propiciem a sensibilização, por parte destes, quanto às necessidades características das mulheres que vivenciam o contexto prisional. Além disso, é fundamental que os profissionais repensem acerca dos seus valores e de suas ações para garantir a qualidade no cuidado e a promoção de saúde dessa população, recepcionando a mulher com respeito, ética e dignidade, além de incentivar o resgate do papel ativo no processo de parturição, e a não aceitação de qualquer tipo de discriminação e da submissão quanto aos procedimentos a serem realizados.

\section{CONFLITOS DE INTERESSES}

Nenhum conflito financeiro, legal ou político envolvendo terceiros (governo, empresas e fundações privadas, etc.) foi declarado para nenhum aspecto do trabalho submetido (incluindo mas não limitando-se a subvenções e financiamentos, conselho consultivo, desenho de estudo, preparação de manuscrito, análise estatística, etc).

\section{REFERÊNCIAS}

1. Arruda SN. Sistema carcerário brasileiro: A ineficiência, as mazelas e o descaso presentes nos presídios superlotados e esquecidos pelo poder público. Revista Visão Jurídica, edição 59 [Internet]. 2011 [Acesso em 26 de abril de 2015]. Disponível em: http://revistavisaojuridica.uol.com. br/advogados-leis-jurisprudencia/59/sistema-carcerariobrasileiro-a-ineficiencia-as-mazelas-e-o-213019-1.asp

2. Juízes A, Terra I, Cidadania T, Carcerária P, Cnbb N, Defesa I De et al. Relatório sobre mulheres encarceradas no Brasil. 2007;1-61.

3. Bispo TCF, Nunes FN, Rebouças LT, Dos Santos SM, Sacramento RALA. Percepções das Gestantes e Puérperas Presidiárias Acerca Do Contexto Carcerário. Rev Enferm Contemp. 2016;5(1):43-50. doi: 10.17267/2317-3378rec. v5i1.835

4. Amaral MF, Bispo TCF. Mães e filhos atrás das grades: um olhar sobre o drama do cuidar de filhos na prisão. Rev Enferm Contemp. 2016;5(1):51-58. doi: 10.17267/23173378rec.v5i1.836
5. Brasil. Ministério da Saúde. Plano nacional de saúde no sistema penitenciário. Brasília. DF. 2005.

6. Brasil. Presidência da República, Subchefia para Assuntos Jurídicos. Lei $n^{\circ} .11 .942$ de 28 de maio de 2009. Dá nova redação aos arts. 14, 83 e 89 da Lei no 7.210 , de 11 de julho de 1984 - Lei de Execução Penal [Internet]. Brasília, DF; 2009. [acesso em 10 de março de 2016]. Disponível em: http://www.planalto.gov.br/ccivil_03/_Ato20072010/2009/Lei/L1 1942.htm\#art1

7. Brasil. Conselho Nacional de Justiça. Regras de Bangkok: Regras das Nações Unidas para o Tratamento de Mulheres presas e medidas não privativas de liberdade para mulheres infratoras. Série tratados internacionais de direitos humanos. Brasília. DF. 2016.

8. Brasil. Ministério da Justiça. Secretaria de Estado da Saúde de São Paulo. Centro de documentação. Portaria Interministerial $n^{\circ} 210$, de 16 de Janeiro de 2014. Brasília. DF. 2014.

9. Brasil. Ministério da Saúde. Secr Exec Núcleo Técnico da política Nac Humaniz Humaniza SUS. Brasília. DF; 2004. p. $1-19$.

10. Fonseca JJS. Metodologia da pesquisa científica. São Carlos Serviço Bibl e Informação ... [Internet]. 2002;1-127.

11. Gil AC. Como elaborar projetos de pesquisa. 4. ed. São Paulo: Atlas; 2007.

12. Gerhardt TE, Silveira DT. Métodos de Pesquisa. Série Educação a Distância. 1.ed. Rio Grande do Sul: Universidade Federal do Rio Grande do Sul; 2009.

13. Boni V, Quaresma S. Aprendendo a entrevistar: como fazer entrevistas em Ciências Sociais. Em Tese. 2005;2(3):68-80.

14. Minayo MCS. Ciência, Técnica e Arte: O Desafio Da Pesquisa Social. Minayo, MCS Pesqui Soc Teor e criatividade. $2001 ; 80$.

15. Brasil. Ministério da Justiça. Departamento Penitenciário Nacional - DEPEN. Levantamento de Informações Penitenciárias. Brasília. DF. 2014.

16. Bispo TCF, Aleixo C, Oliveira CA, Neto EAF. Saúde sexual e reprodutiva no contexto da prisão: vivências de presidiárias de Salvador-Ba. Rev Enferm Cont. 2015;4(2):109-120. doi: $10.17267 / 2317-3378$ rec.v4i2.747

17. Nicolau AIO, Ribeiro SS, Lessa PRA, Monte AS, Ferreira RCN, Pinheiro AKB. Retrato da realidade socioeconômica e sexual de mulheres presidiárias. ACTA Paul Enferm. 201 2;25(3):386-92. doi: 10.1590/S0103$\underline{21002012000300011}$

18. Brasil. Política Nacional de Atenção Integral à Saúde da Mulher : Princípios e Diretrizes. Brasília. DF. 2004. 44 p. 
19. Martins TP, Leite CKS. Políticas públicas para mulheres encarceradas no Brasil: trajetória de uma agenda governamental travada. In. Encontro Nacional de Pesquisadores em Gestão Social, n. 6. 2012 ; São Paulo. p. $1-12$.

20. Lucyk JDM. Necessidades nutricionais e consumo alimentar na gestação : uma revisão. Com Ciência Saúde. 2008; 19(4):353-63.

21. Santos LMP, Pereira MZ. Efeito da fortificação com ácido fólico na redução dos defeitos do tubo neural. Cad. Saúde Pública. 2007;23(1):17-24. doi: 10.1590/S0102$311 \times 2007000100003$

22. Brasil. Ministério da Saúde. Pré-natal e Puerpério: atenção qualificada e humanizada. Brasília. DF. 2005.

23. Barros SMO. Enfermagem Obstétrica e Ginecológica: guia para a prática assistencial. 2. ed. São Paulo: Roca; 2009.

24. Oliveira BRG, Collet N, Viera CS. A humanização na assistência à saúde. Rev Lat Am Enfermagem. 2006; 1 4(2):277-84. doi: 10.1590/S010411692006000200019

25. Brasil. Decreto $n^{\circ} 8.858$, de 26 de setembro de 2016. Regulamenta o disposto no art. 199 da Lei $n^{\circ} 7.210$, de 11 de julho de 1984 - Lei de Execução Penal. Diário Oficial da União. 2016 set. 27. 